REVIEW ARTICLE

\title{
Conceptual frameworks facilitate integration for transdisciplinary urban science
}

\author{
Weiqi Zhou (iD) ${ }^{1,2 \otimes}$, S. T. A. Pickett $\mathbb{1 D}^{3}$ and Timon McPhearson $\mathbb{i D}^{3,4,5}$
}

There are urgent calls for developing a comprehensive and globally-relevant urban science that emphasizes convergence among disciplines and practice. Advancing theory and conceptual frameworks is critical to developing a new urban systems science. We synthesize five frameworks that address features identified in calls for global urban science. The frameworks address the overarching urban conditions of complexity, diffuseness, connectivity, and diversity of cities across the globe. The frameworks also help evaluate how a project or study may advance sustainability. The metacity concept, a spatially scalable representation of mosaic change in urban systems, demonstrates how the frameworks apply to increasingly extensive, spatially heterogeneous, and dynamic urban regions. The metacity concept helps avoid static and isolated plans and management approaches and provides a conceptual foundation for an interdisciplinary urban systems science. The frameworks suggest a practical checklist that may help interventions, strategies, and research better align with goals for transforming urban systems toward sustainability.

npj Urban Sustainability (2021)1:1; https://doi.org/10.1038/s42949-020-00011-9

\section{ADVANCING URBAN SYSTEMS SCIENCE FOR SUSTAINABILITY}

Urban regions are massively changing in demographics, socioeconomic processes, urban form, technologies, and environment ${ }^{1}$. These transformations affect sustainability ${ }^{2}$ and have spillover effects on virtually all areas of the Earth ${ }^{3}$, suggesting that cities are key to global sustainability ${ }^{4,5}$. The need to understand these interacting transformations and to solve the complex problems they cause, has led to calls for a new global urban science ${ }^{6,7}$. Advancing global urban sustainability involves paradigm shifts" ${ }^{1}$ or "convergence science," defined as "integrating knowledge, methods, and expertize from different disciplines and forming novel frameworks to catalyze scientific discovery and innovation ${ }^{\prime \prime 8,9}$. To help meet the challenge of convergence science, we here synthesize established conceptual frameworks from the interdisciplinary science of socialecological-technological systems (SETS) ${ }^{10,11}$

The calls for a global urban science ${ }^{1,6,9,1 i-13}$ identify the goals of that new science. It must address: (1) the joint social, ecological, and technological nature of urban systems ${ }^{14,15}$; (2) the role of disruptive actions in urban transformation ${ }^{16}$; (3) the capacity of urban systems to adapt ${ }^{17} ;$ (4) the interactive and dynamic complexity of urban spatial form ${ }^{18}$; and (5) transboundary flows at multiple scales ${ }^{13}$. The new emerging urban theory must account for the major conditions of global urbanization, that is complexity, diffuse boundaries, connectedness, and diversity. The theory must possess mechanistic frameworks that operationalize the theory in actual situations (Fig. 1). We present a novel synthesis of existing frameworks to facilitate the "synthetic and holistic enquiry" that a global urban science ${ }^{1}$ can bring to urban agendas such as Sustainable Development Goal 11-to "make cities and human settlements, inclusive, safe, resilient, and sustainable ${ }^{\prime 12}$.

The synthesis uses the major conditions of global urbanization to identify key frameworks-(1) the human ecosystem, (2) disturbance, (3) resilience, (4) dynamic heterogeneity, and (5) the continuum of urbanity-that can support sustainability solutions. The synthesis also employs a scalable, overarching "metacity" concept that conceives of urban areas as multifaceted, spatially heterogeneous, and dynamic regional systems (Fig. 1). The synthesis of frameworks can be employed to evaluate whether interventions aimed at urban sustainability address the global urban conditions. The synthesis is exemplified by four cases woven through the text: extreme urban heat, the role of vacant land in urban cores, green stormwater infrastructure, and a new urban development in China.

\section{FRAMEWORKS FOR LINKING AND TRANSLATING GLOBAL URBAN CONDITIONS}

To ensure the comprehensive synthesis that convergence science demands ${ }^{9}$, we combine frameworks that relate to each of the widely recognized major conditions that characterize urban systems and dynamics $^{19}$ : (1) complexity, (2) diffuseness, (3) connectivity, and (4) diversity. These four global urban conditions are grand generalizations that must be linked to each other and translated to different places and contexts ${ }^{19}$. Conceptual frameworks help achieve translation from general states to specific places. The breadth of the literature on urbanism suggests that no single framework covers all global urban conditions. Consequently several frameworks must be synthesized to promote urban systems science ${ }^{20,21}$.

Based on the phenomena previously identified as requirements for global urban science ${ }^{1,6,9,11-13}$, we identified five frameworks of SETS interactions underlying urban form and change. These frameworks are relevant to the conceptual space defined by the four global urban conditions, as well as to the practical goals articulated for global urban science. The power of the frameworks for advancing urban science is not their novelty or distinctness, but rather how they complement each other. The selected frameworks are: (1) the human ecosystem ${ }^{22,23}$, (2) disturbance or perturbation $^{10,24}$, (3) resilience ${ }^{25,26}$, (4) dynamic heterogeneity ${ }^{27,28}$, and (5) the "continuum of urbanity", which specifies the mechanisms and scales of connectivity across urban systems ${ }^{29}$.

\footnotetext{
${ }^{1}$ Research Center for Eco-Environmental Sciences, Chinese Academy of Sciences, Beijing 100085, People's Republic of China. ${ }^{2}$ University of Chinese Academy of Sciences, Beijing, People's Republic of China. ${ }^{3}$ Cary Institute of Ecosystem Studies, Box AB, Millbrook, NY 12545, USA. ${ }^{4}$ Urban Systems Lab, The New School, 79 Fifth Avenue, 16 th Floor, New York, NY 10003, USA. ${ }^{5}$ Stockholm Resilience Centre, Stockholm University, SE-106 91Kräfriket 2B, Stockholm, Sweden. ${ }^{凶}$ email: wzhou@rcees.ac.cn
} 


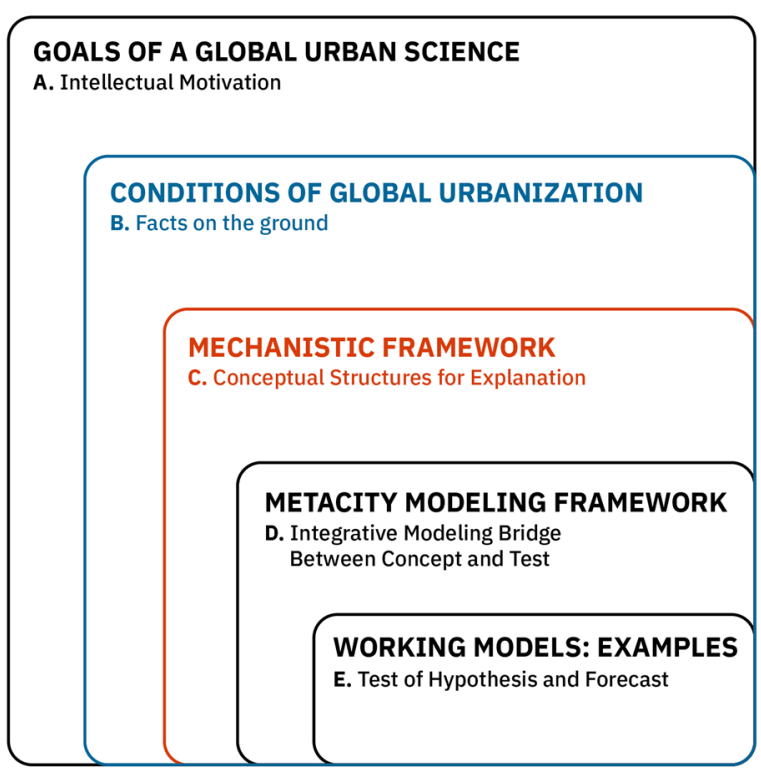

Fig. 1 The structure of the synthesis. The goals desired for global urban science motivate the synthesis (A). The synthesis must address the prevailing conditions of global urbanization (B). Mechanistic frameworks are employed to translate the conceptual content of the theory to interactions and constraints that operate in actual or proposed urban situations (C). The metacity concept provides a representational and modeling strategy to apply the frameworks at various scales to explain urban spatial and temporal dynamics and processes (D). The synthesis is supported by reference to working models of heat waves, vacancy in urban cores, green stormwater infrastructure, and new urban development (E).

We first describe the frameworks, and then connect them to the global urban conditions. A final synthetic step shows how the five frameworks can operate within an inclusive spatial and dynamic urban concept-the metacity - that will be defined below. We end by highlighting practical contributions of our synthesis to design for sustainability.

\section{FRAMEWORK 1: THE HUMAN ECOSYSTEM}

An expression of a complex systems view is the human ecosystem framework ${ }^{22,30}$, which combines sociological and biophysical perspectives. The human ecosystem, also known by terms such as social-ecological systems ${ }^{14,23,31,32}$, social-ecological-technological systems (Fig. 2) $)^{11,15}$, or the total human ecosystem ${ }^{33}$, considers urban areas as a kind of comprehensive ecosystem. Thus, the human ecosystem is constituted not only the biological and physical components from the fundamental ecosystem idea, but includes construction, buildings, infrastructures, technologies and the full range of social, economic, and cultural manifestations of human life ${ }^{34-36}$. The human ecosystem is fundamental to the synthesis presented here and is co-produced by interacting social and natural processes $^{37,38}$.

\section{FRAMEWORK 2: DISTURBANCE}

Ecology considers that natural systems are subject to periodic structural disruptions or disturbances ${ }^{39,40}$. Urbanism likewise acknowledges disruptive events such as the "creative destruction"41 of capitalism. The disturbance framework ${ }^{42}$ readily applies to socialecological-technological urban systems ${ }^{10}$. The 1995 Chicago heat wave (Fig. 3) illustrates the disturbance framework. The model shows how extreme events interact with the structure of socialecological-technological systems to translate external drivers into system effects and to generate change. Disturbance is a process initiated by an event, in this case a massive, regional system of hot dry air that persisted for 5 days, that disrupts the structure of a system. The vulnerability of the system to disruption, indicated by human morbidity and mortality in this case, is determined by the structure, composition, and interactions within it. Relevant structures in Chicago were poverty, capacity of the medical establishment, and lack of a heat warning system. Whether the system recovers or transitions to another state is determined by the resources that can be deployed toward recovery and the capacity for development within system components.

\section{FRAMEWORK 3: RESILIENCE}

Resilience describes the mechanisms of change or persistence in complex systems, and provides a way to determine when a system has shifted to a new state ${ }^{43}$. The concept acknowledges the difference between resilience in engineered systems that have a straightforward function, versus resilience in complex systems that have non-linearities, open ended change, and selforganization $^{43,44}$. Applying resilience to social-ecological systems and more recently to SETS has been an important advance ${ }^{14,45,46}$.

Resilience theory posits that systems accumulate social and ecological complexity as they develop from phases where system components depend upon freely available resources toward structures that conserve resources. Given concerns about climate change impacts in cities, examining events such as the 1995 Chicago heat wave and how it disrupted a structurally conservative systems is informative. During the 1995 heat wave, high mortality occurred where social and financial resources were apparently insufficient to allow persons to avoid the physiological stresses of the extraordinary heat, stagnant air, and high humidity at the surface. The foci of mortality illustrate a "poverty trap" in the resilience cycle ${ }^{47,48}$. Literal poverty was associated with poor access to air conditioning and reluctance of empoverished residents to open ground floor windows for ventilation. A figurative poverty trap was the limited capacity of the medical system to deal with unprecedented demand in the 1995 heatwave. Organizational "lockin" was seen in the inability of the city to warn residents in advance due to lapsed memory about prior extreme heat waves, built-in barriers to communication among different emergency services, and the inability to quickly boost emergency room and ambulance services. However, during reorganization after the heat wave, the Chicago urban system exhibited adaptive capacity by vesting new powers in the Department of Emergency Management (which later added public communication to its mandate) to coordinate response. The Chicago heat wave also stimulated adaptation of federal agencies to deal with urban heat waves. Indeed, urban heat waves are now a primary concern for sustainable urban futures ${ }^{49,50}$. A 1999 heat wave in Chicago resulted in fewer than 200 excess deaths, demonstrating system adaptation to extreme heat.

\section{FRAMEWORK 4: DYNAMIC HETEROGENEITY}

The framework of dynamic heterogeneity places the temporal changes during the resilience cycle in a spatial context. Spatial heterogeneity is a major aspect of cities ${ }^{51-53}$ and is both raw material and output of urban planning ${ }^{54}$. Disturbance reacts to existing heterogeneity and generates new patterns of urban heterogeneity.

The 1995 Chicago city-wide mortality statistics are stark, but racial and economic segregation suggest that vulnerability and response to heat waves may be highly spatialized ${ }^{55-58}$ (Fig. 4). Dynamic heterogeneity suggests that the social and material differences identified at coarse scales in Chicago would have finerscale implications for interaction of social and biophysical heterogeneities over time (Fig. 5). 


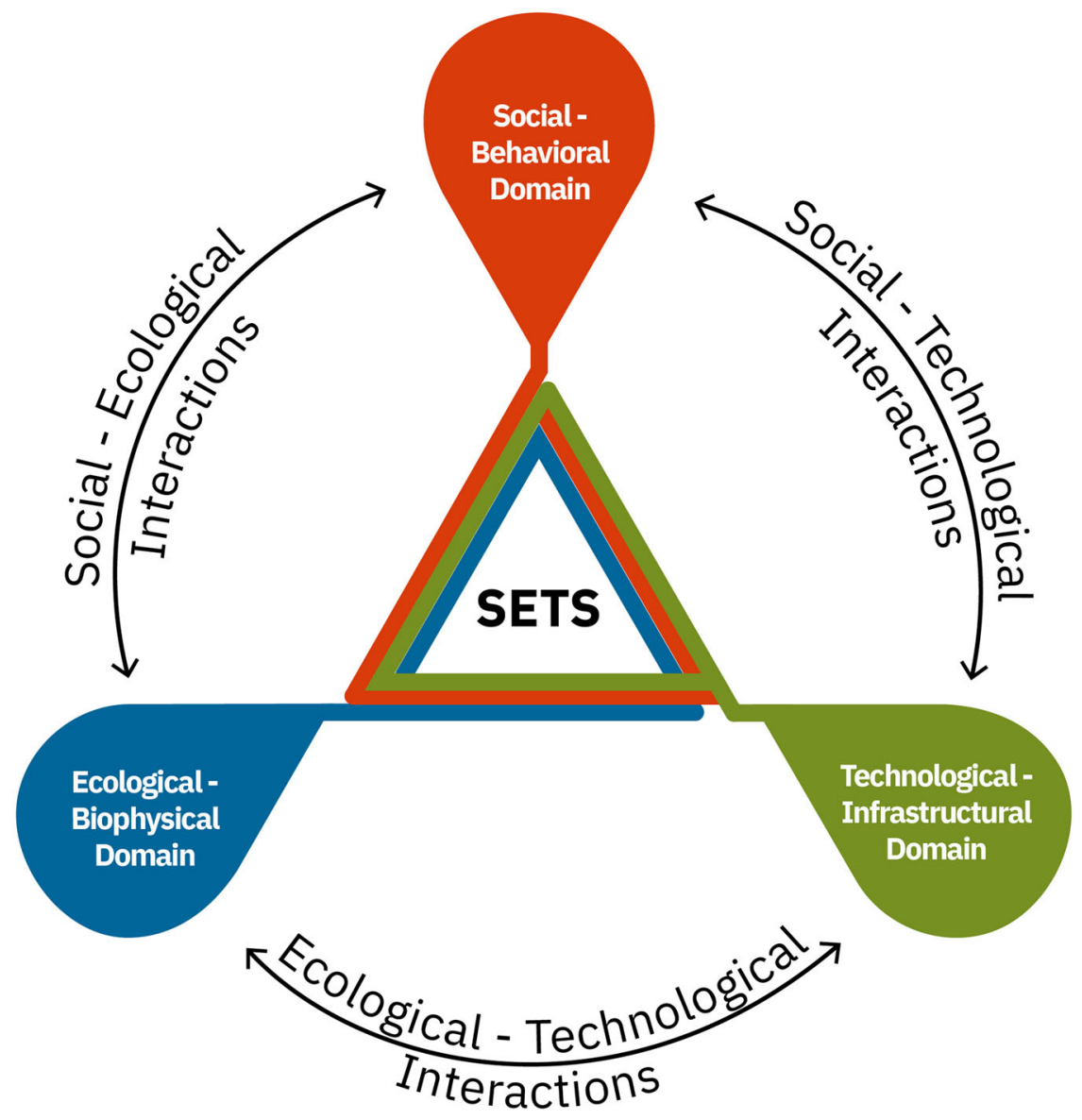

Fig. 2 The human ecosystem as social-ecological-technological systems (SETS). It emphasizes the social-behavioral, ecological-biophysical, and technological-infrastructural domains and their interaction (Adapted from ref. ${ }^{75}$ ).

\section{FRAMEWORK 5: CONTINUUM OF URBANITY}

The continuum of urbanity is a new framework that emphasizes modes and effects of connectivity within and among urban regions ${ }^{29}$. It posits that all locations are a mixture of characteristics that are urban and characteristics that are rural or wild. Sites can be ranked by their degree of urbanness or urbanity ${ }^{29}$. Each site is characterized by (1) livelihood, or how people support themselves; (2) lifestyle, or how they identify socially and express group identity via consumption and leisure; (3) how the site and inhabitants are connected locally and with distant areas through migration, commuting, investment, information, energy, resources, and waste; and (4) the structure and perception of the area as a social-ecological-technological system. The mixture of livelihoods, lifestyles, connections, and social-ecological structures position a site on the conceptual continuum.

Connectivity across and among urban regions relative to heat wave preparedness exemplifies the a key aspect of the continuum of urbanity: the exchange of information. The lessons from the 1995 Chicago and European heat waves in the 21 st century (e.g., 2003, 2006, 2007, 2015, 2018, and 2019), and from subsequent supra-regional heat waves that affected Chicago and other American cities have been shared widely. The improved knowledge of the causes of and social factors that correlate with mortality during extreme heat events has improved how cities prepare for the unpredictability of extreme heat in relation to social vulnerabilities. This knowledge in turn has helped improve emergency planning or mitigation in many cities. Thus, the resilience cycle combines with the continuum of urbanity in heat wave adaptation.

\section{LINKING AND TRANSLATING FRAMEWORKS TO THE GLOBAL URBAN CONDITIONS}

The overarching global urban conditions provide the context for ${ }^{59}$ the frameworks, each of which links to several of the contexts (Fig. 1):

- Complexity in urban systems is explained by the human ecosystem framework, with its combined social-ecological composition of urban systems. Complexity is also generated and modified by disturbance as a mechanism of urban change. The resilience cycle requires adaptive capacities, some of which function via compartmentalization, which is a dimension of spatial and organizational complexity.

- Diffuseness is associated with porous boundaries, resulting in gradients of urban differentiation that characterize some adaptive capacities for resilience ${ }^{19}$. Risk spreading is an adaptive capacity of resilience that relies on diffuseness. Dynamic heterogeneity, because it may shift patch identity and contrast over time, and involve both social and biophysical drivers and responses, can generate diffuseness in urban systems. But diffuseness appears most compellingly in the continuum of urbanity, reflecting the urban/rural integration of individual patches at many scales.

- Connectedness appears in how the resilience cycle redeploys resources after disturbance. A lack of internal connectedness may prevent redistribution of resources. Connectedness may also appear in dynamic heterogeneity when nearby or distant patches supply agents of change that can move to or distally influence focal patches. Furthermore, connectedness, whether local or global, is a primary feature of the continuum of urbanity. 
DISTURBANCE AS PROCESS

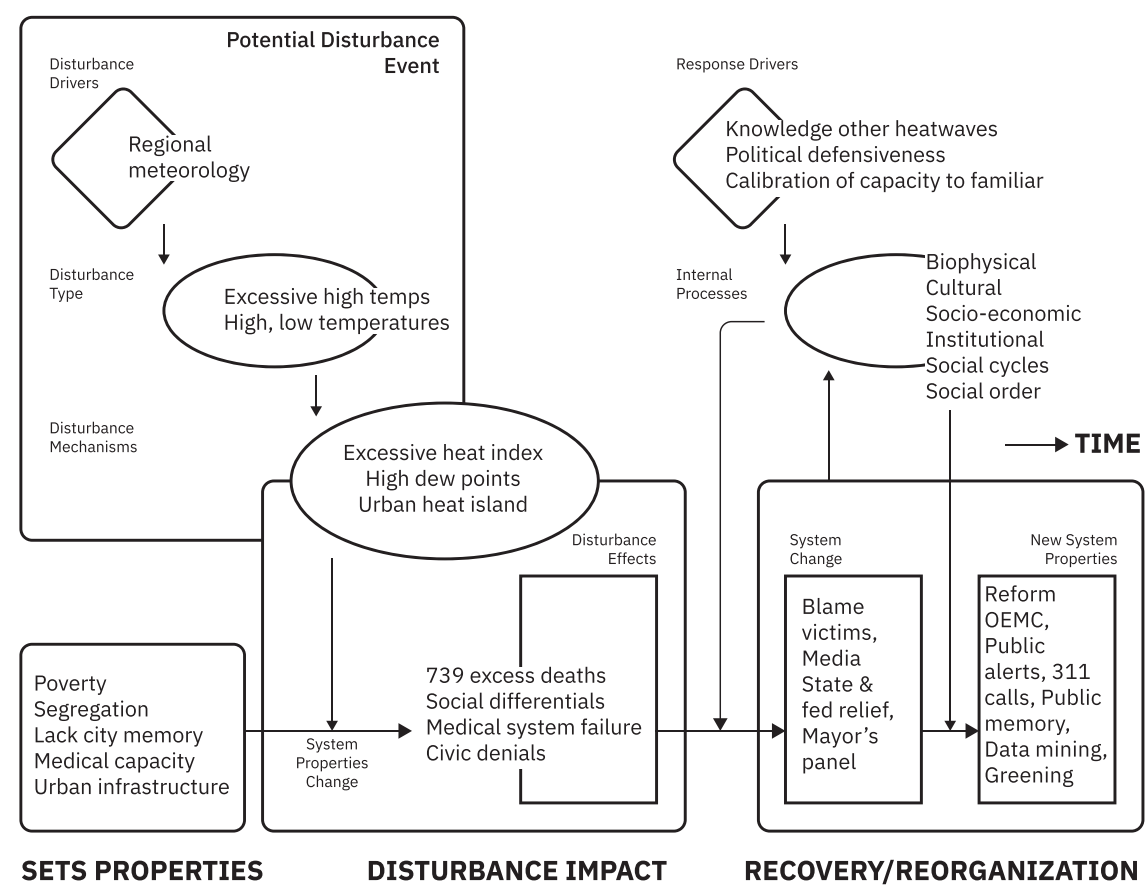

Fig. 3 A model template for disaggregating disturbance as a process, illustrated by the Chicago heat wave of July, 1995. Events embody mechanisms (forces) which interact with the existing structure of the system to generate change in the system structure. Subsequently, the system can respond based on the changes caused by the disturbance event interacting with the capacities and drivers in the post-disturbance system. The system properties shown in the Recovery/Reorganization box are those that will interact with subsequent disturbances. OEMC stands for Office for Emergency Management and Communication. The number 311 refers to the service request line in many American cities, including Chicago. The time arrow toward the right of the diagram indicates that subsequent instances of disturbance and response can follow this one. The template is modified from Grimm et al. ${ }^{10}$.

- Diversity of the types and structures of different cities across the globe relies mainly on two frameworks. Dynamic heterogeneity diversifies the local variety of social and biophysical disturbance agents, thus contributing to the global differentiation of urban systems. The continuum of urbanity, which recognizes the power of teleconnections, also acknowledges that regional ecological and social conditions can affect how different areas respond to or participate in those teleconnections.

\section{THE METACITY AS A TOOL FOR INTEGRATION}

The metacity is a concept that has great synthetic power, and so we introduce this new concept here to facilitate the transition to transdisciplinary convergence science. A metacity is an urban mosaic, at any scale, that consists of patches differentiated by their interacting biophysical, social, and technological components ${ }^{60,61}$. The concept focuses not only on spatial differentiation among patches, but also on the temporal dynamics of individual patches and the resultant changes over time in the mosaic as a whole (Fig. 6). Patches may be differentiated by their hybrid structures, and by the contrasting kinds or levels of processes that each patch supports. Furthermore, patches can be connected to greater or lesser degrees by flows of energy, organisms (including people), information, and materials. Consequently, a metacity is a comprehensive way to represent the spatial, temporal, structural, and process-based features of any urban system. A metacity model can be applied within neighborhoods, based, for example on contrasts among property parcels in a block. The same conception based on heterogeneity, change, and linkages, can be applied to different districts within a metropolis, where contrasts might be based on various mixtures of housing, business, and associated open space, and where changes might appear through time based on changes in economic investments, human migration, or vegetation dynamics. At a coarser scale, industrial firms themselves may come and go based on global patterns of regulation, taxes, or wages.

The spatially nested hierarchies of metacities may contain crossscale interactions. Investments in high speed, limited access highways at coarse scales across a metropolis can generate changes in residential density of different fine scale neighborhoods. Changes in urban patchiness in the Chiang Mai region of Thailand illustrate some of the kinds of changes that occur over time in the spatial and functional mosaic of an urbanizing region ${ }^{62}$. The Chang Mai region as a metacity is responding to increasing urban population, shifts from farming to support of tourists, consolidation of handicrafts into factory zones, the adoption of private villa-style housing in contrast to templecentered village compounds, and the addition of high speed and new feeder roads, among others. The spatial, temporal, and organizational or functional mapping supported by the metacity concept brings these shifting conditions and processes together. Thus, it is an ideal synthetic tool to show the linkages among the global urban conditions and the five mechanistic frameworks.

Another example of metacity dynamics is the changes in vacant land in cities. We focus on the fine scale process of demolition and construction in an urban parcel in Shanghai (Fig. 6B) as one illustration of how patches are created or changed. The pattern of vacancy at any one time aggregates up to coarser scales, for example that represented by the urban core of Shanghai (Fig. 6C). In turn, coarser scale mosaics assimilate the fine and mediumscale processes of parcel change across the multiple cities and the interstices in the Yangtze River Delta urban megaregion (Fig. 6D). Each one of the scales-from neighborhood to the entire Yangtze River Megaregion-is a metacity. 


\section{CHICAGO HEAT WAVE}

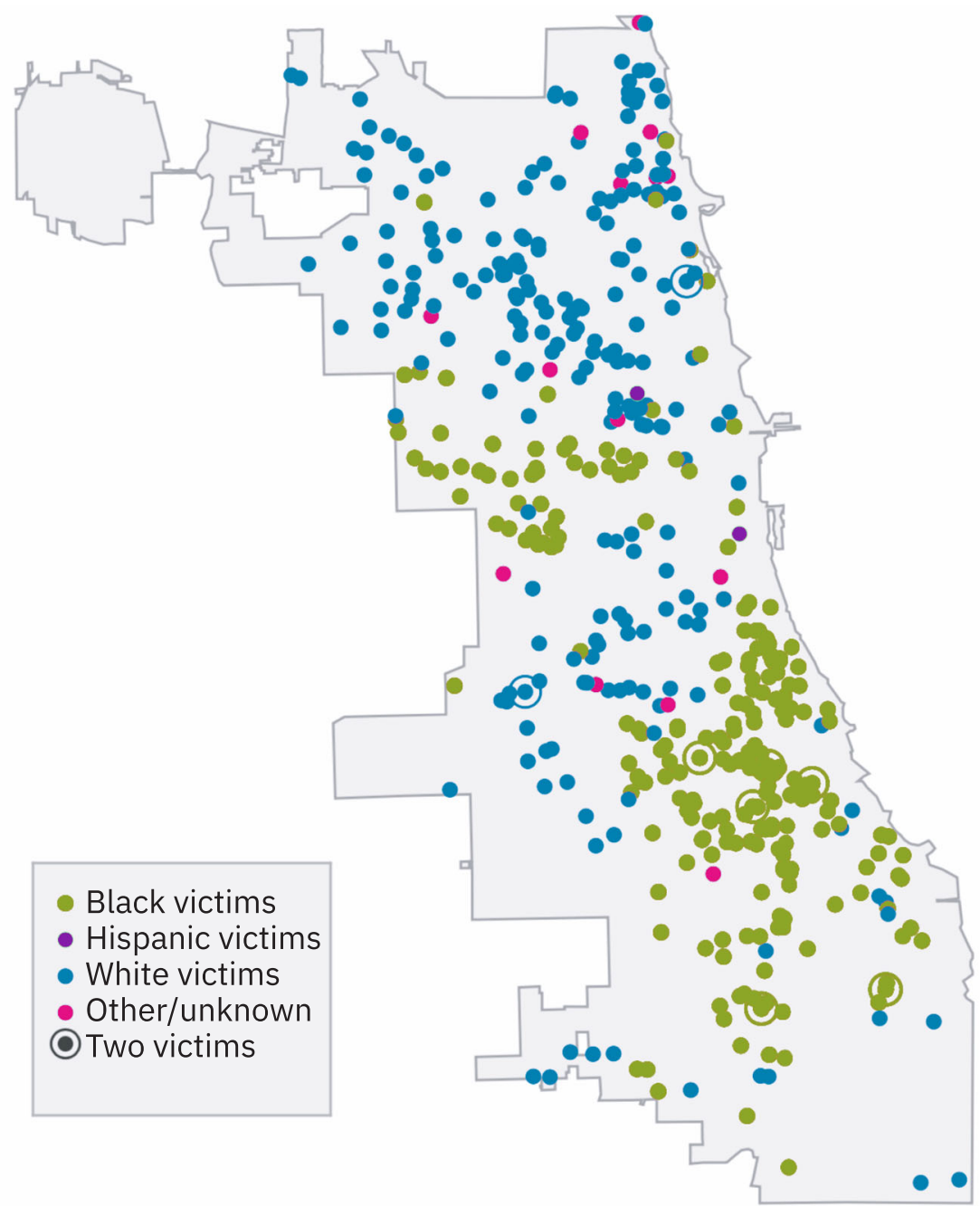

Fig. 4 The spatial distribution and racial classification of the $\mathbf{7 3 9}$ deaths from the July $\mathbf{1 9 9 5}$ heat wave in Chicago. Source: Mike Thomas in July 2015 issue of Chicago Magazine. The map is interactive in the online magazine. ๑ 2015 Chicago Magazine. All rights reserved. Distributed by Tribune Content Agency, LLC. Used by permission.

The metacity also has synthetic power because its fundamental, component ideas resonate with different disciplines and professions. The metacity has roots in architecture ${ }^{59}$, emphasizing its relevance to convergence between scientific knowledge and the praxis of urban planning and design. It also parallels ecological concepts such as the metapopulation and metacommunity ${ }^{63}$. In effect, the metacity applies "patch dynamic" or shifting-mosaic ${ }^{28,62}$ thinking to social-ecological-technological urban regions ${ }^{22}$. Although the metacity concept was introduced elsewhere ${ }^{64}$, this is its first use as a synthetic tool for diverse urban frameworks.

We propose the metacity concept can serve as a central node in a nested theoretical structure that includes the four global urban conditions on its higher level as constraints or contexts, while processes/mechanisms identified by the five contributing frameworks can be adopted as hypotheses and measurable parameters on its lower level (Fig. 7). Consequently, the metacity serves as a theoretical condenser or nexus that brings both very general constraints and very specific mechanisms together. The global urban conditions are linked with numerous urban problems, such as sprawl, governance, or pollution associated with motorized transport. Consequently, identifying the links of the metacity to these conditions and using the metacity as a conceptual template bringing together the processes or mechanisms identified by the five frameworks may help strategize locations and kinds of co-produced urban solutions.

\section{THE METACITY CONFORMS TO THE FOUR GLOBAL URBAN CONDITIONS}

The four global urban conditions provide the high level constraints or contexts for the metacity as a modeling approach. Its relationship to the four global urban conditions is described below, with each global urban condition italicized. The metacity, as defined by McGrath and colleagues ${ }^{59,60,62,63}$, has the following key characteristics relevant to our synthesis. It:

- Is not just about size; rather it focuses on structure, process, and dynamics. Nor is it only about biology and physical features, but it also encompasses society and technology. Thus, the metacity applies the process-oriented human ecosystem framework and the global condition of urban complexity.

- Applies to any spatial scale, from households and parcels to extensive urban regions. Thus the metacity incorporates the 


\section{REGIONAL HEATWAVE}

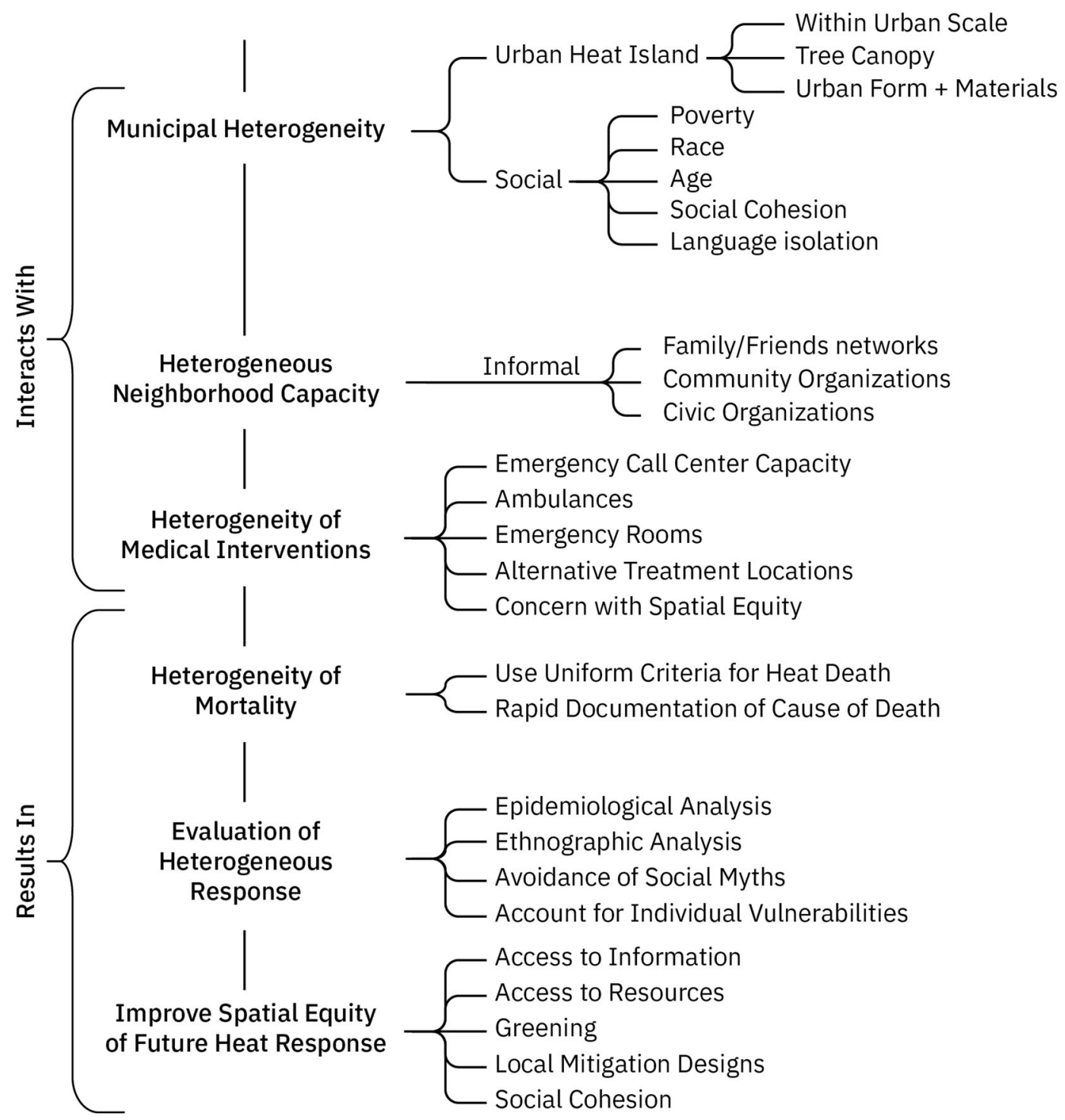

Fig. 5 Dynamic heterogeneity as cause and consequence in urban systems illustrated by heterogeneity of social factors that can interact with heterogeneity in the urban heat island during a heat wave (the first three items in the left hand column), followed by subsequent effects and responses that may differ in space (the final three items on the left). Although the interacting factors and recommendations for improvement are well known from the Chicago 1995 and other heat waves, the spatial differentials for most of the steps in the cascading dynamics of heterogeneity have not been quantitatively examined at within-city scales. The ultimate concern with equity is also an aspect of heterogeneity. This is a hypothetical model that can guide future research.

global urban condition of connectedness at various scales and distances.

- Is not just about isolated patches, but instead explores the consequences of transboundary flows and influences. Thus, the metacity operates under the conditions of diffuseness and connectedness, and applies to diverse emerging forms of urbanization in the global south and in non-industrial areas.

- Is not about fixed spatial arrangements, but deals with mosaics that shift over time in composition, configuration, and connection. Thus, it is ideally suited to the unpredictable and linked transformations of diverse global urban changes resulting from local or regional drivers.

- Does not rely on an equilibrium distribution of states or an end point. Thus, the metacity permits multiple trajectories and goals of urban change, and shows how the condition of urban diversity arises.
Consequently the four global urban conditions (Fig. 7) can be considered to impose top down constraints that the metacity must accommodate. But the concept can also integrate bottom up processes and mechanisms, as we show in the next section.

\section{THE METACITY INTEGRATES THE FIVE URBAN FRAMEWORKS}

The mechanistic substance of the metacity as a model approach is provided by the five frameworks and their component processes. Each of the frameworks contains "bottom up" drivers or causes of structure and change in a metacity. The metacity provides a coherent, generalizable conceptual template for urban spatial dynamics. Based on the general template, a specific metacity model at a particular scale would be populated with various processes or mechanisms identified by the five contributing frameworks. The mechanisms that each framework includes are 
A
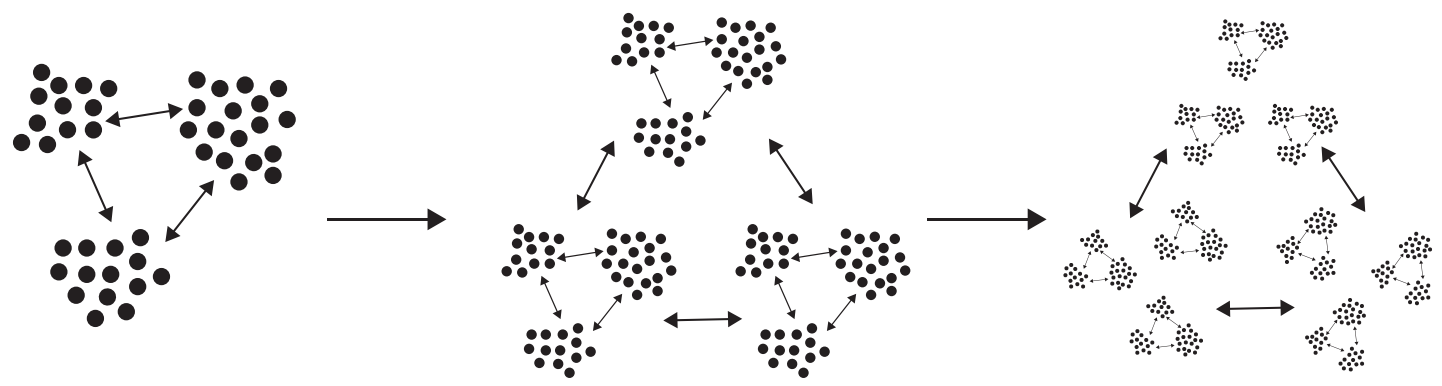

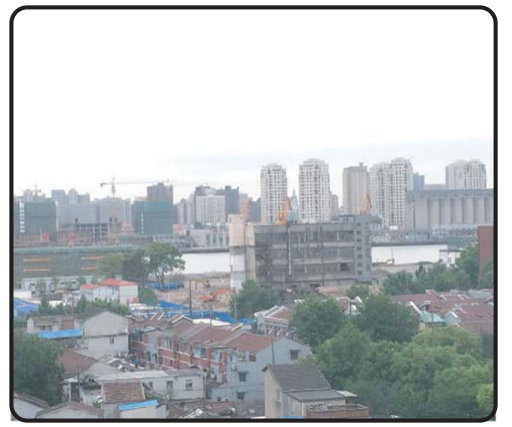

B

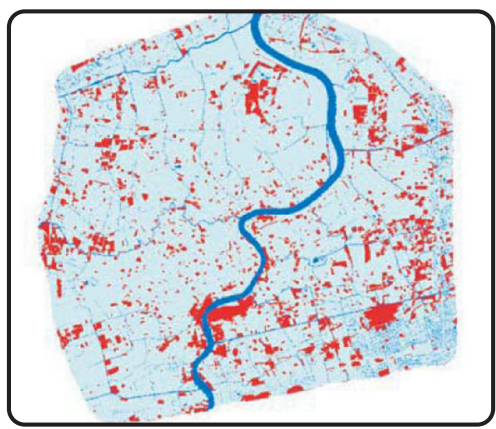

C

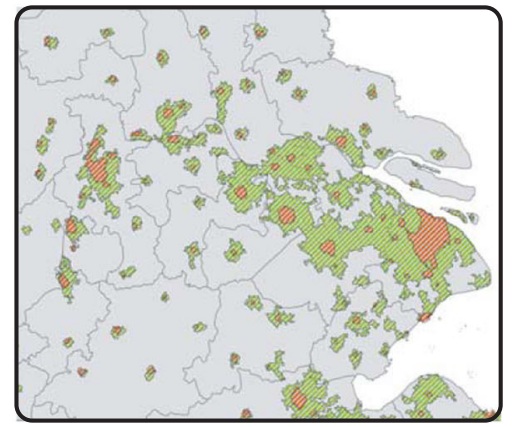

D

Fig. 6 The concept of the metacity. A is the basic concept of metadynamics showing discrete but interacting patches at different scales (modified from Mihaljevic 2012). B-D illustrate metadynamics in Shanghai, China at increasing spatial scale from left to right. B shows a patch under construction in the urban core of Shanghai, which is intricately tied to integrated social-ecological systems. C shows the spatial distribution of vacant land within the urban core area of Shanghai in 2010, and the diverse types of vacant land generated from a variety of social-economic processes. D is the spatial distribution of urban growth from 1992 to 2010 in the Yangtze River Delta (YRD) megaregion of which Shanghai is a part. These illustrations neglect the variety of material, human, and informational transboundary flows that actually exist across the different mosaics. Also not shown are the larger national and global mosaics or agglomerations of urban nodes and metacities with which Shanghai and the YRD interact.

the factors and actions that generate change in the spatial mosaic of any urban system. The metacity concept, as the central node in a nested theoretical structure, relies on the five frameworks to articulate the mechanisms that specific models can employ (Fig. 7). Because the metacity is a scalable concept, it links the five frameworks and so represents mechanisms and applications on many scales. The scale-flexible nature of the metacity is useful because 21st century urbanization has itself become a multi-scalar phenomenon ${ }^{65,66}$. The metacity does not explode because it uses five diverse frameworks; rather it is a conceptual device that brings the mechanistic detail of the five frameworks together.

\section{A SHARED TOOL FOR CO-PRODUCED SOLUTIONS}

There are practical benefits of the metacity framework for planning or management. (1) The metacity prevents practitioners from assuming cities are static. Some models and many plans are fixed, and management is often neglected after a project is constructed. (2) The metacity points to factor interaction in city change, a subject of academic and real-world interest. This counters the factor-by-factor approach to cities often embedded in governance silos or professional disciplines (e.g., traffic, waste, utilities). (3) It also helps keep developers, designers, or researchers who may focus on particular cities or neighborhoods, from seeing their work as spatially isolated. (4) In practice, the metacity and the frameworks it operationalizes call for plans and management to account for ongoing flows in the mosaic. (5) The scalar openness of the metacity helps practitioners and researchers discover and work with the flows from distant locations, and it sees specific sites and projects as reciprocally related to other places. (6) Finally, it helps policy makers and residents understand the need to manage the ongoing processes of change in their metacity mosaics. The metacity is a conceptual solution to critiques of planning and management as static, isolated pursuits in cities that are actually dynamic and spatially complex in many dimensions.

Combining the metacity and the five frameworks under global urban contexts can provide practical values. The frameworks can be arranged using a logic that begins with the existence of integrated social-ecological-technological systems, and build through important kinds of process (Fig. 8). The logic is that: (1) Urban ecosystems are complex social-ecological-technological systems, and must be modeled as such; (2) These systems, as represented by those explicit models, can be disturbed or disrupted. (3) Once disturbed, they may respond adaptively, exhibiting ecological and social resilience within a domain of attraction, or if adaptive capacities are inadequate, shift to a new domain. (4) Adaptive capacities and outcomes are spatially heterogeneous, resulting in spatial diversity within and among systems. (5) Such differentially adapted and spatially distinct places are integrated social-ecological-technological systems, and can be connected at various scales. The kinds of connection are captured in the continuum of urbanity. The logic can be used to understand ongoing and proposed urban land transformations, as exemplified by both vacancy and growth, phenomenon that all cities undergo, often simultaneously.

For example, understanding land vacancy in post-industrial cities can be enhanced through the logical connections among frameworks. Vacancy and growth are integral parts of social-ecological systems ${ }^{67,68}$; both vacancy and growth represent a structural disturbance; responses to vacancy and growth have intentional and unintentional adaptive responses, or in some cases can expose a lack of adaptive capacity; the distributions of disturbances, capacities, and responses are spatially heterogeneous. 


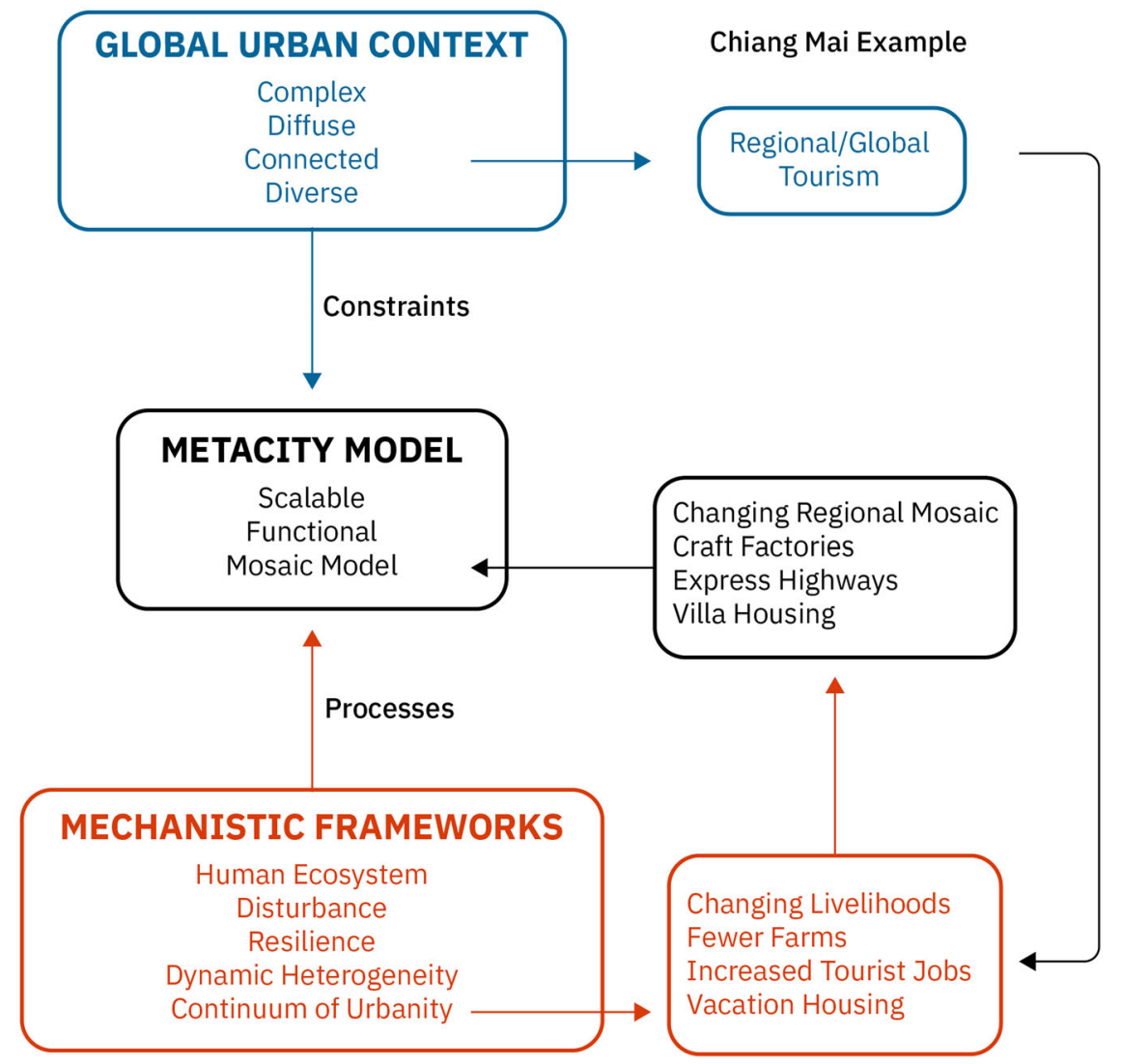

Fig. 7 A nested theoretical structure showing the relationship of the metacity with the four global urban conditions and the five contributing frameworks (Left column). The metacity concept serves as a central node in the nested theoretical structure that includes the four global urban conditions on its higher level as constraints or contexts, while processes or mechanisms identified by the five contributing frameworks can be adopted as hypotheses and measurable parameters on its lower level. The right column shows how some important changes in Chiang Mai, Thailand ${ }^{62}$ correspond to the metacity approach.

Policy makers, managers, property owners, tenants, and users of public space all make decisions about land vacancy and associated amenities, hazards, or burdens ${ }^{69,70}$.

The global conditions and the related mechanistic frameworks (Fig. 8) thus have implications for management and policy. The case of land vacancy as a metacity process provides lessons for improved management or design. For example, demolition is commonly used to address vacancy, but can result in unintentional consequences. Vacancy may reduce property values and social cohesion in impacted neighborhoods, but it also can support urban vegetation, providing the space to expand naturebased ecosystem services such as local and city-wide heat island mitigation ${ }^{67}$. In contrast, the volunteer vegetation that established on vacant lands may not be perceived as an amenity for some neighborhoods.

The frameworks can make a practical contribution to such urban dilemmas because the logical sequence of the frameworks suggests a checklist for assessing sustainability planning. The proposed questions for the checklist are posed below along with two different examples of how they might be applied to green infrastructure as an urban stormwater management intervention, and to a new urban development in China, the Xiong'an New Area. Briefly, the central government of China plans to build the Xiong'an New Area $100 \mathrm{~km}$ south of Beijing, to reduce pressures of overcrowding and pollution in the capital. Newspaper reports (e.g., South China Morning Post, 26 June 2017) concerning this project, announced in April 2017 and ultimately to occupy $2000 \mathrm{~km}^{2}$, indicate that analysis of adaptive capacities has addressed suitability for novel underground development, adequacy of relatively clean subterranean water and potential for water storage infrastructure, earthquake and civil defense security, and geothermal energy resources.

1. Is the system conceived as a system integrating socialecological-technological aspects? Does the plan or intervention address all three of the aspects of the system? Often green stormwater infrastructure in U.S. cities is aimed at satisfying regulatory requirements for stormwater amount or quality. This focuses on the technological component of a city, and can lead to neglect of ecological benefits ${ }^{71}$ or of social burdens imposed on some communities ${ }^{72}$. The massive Xiong'an New Area urban development in China is being planned in a rural lake district. Plans available to the public so far indicate that the intended area is being evaluated for engineering and disaster resilience, but planning for social and ecological sustainability are not yet in evidence.

2. What factors of disturbance act or might act on the system, and how are these factors spatially distributed? Disruption can be generated by social-economic, biophysical-ecological, and technological-infrastructural phenomena (Fig. 2). The Xiong'an New Area has been planned with reference to earthquake and drought disturbance, but it is not clear that heat waves and social cohesion are part of the planning. Changing disturbance regimes may affect green stormwater infrastructure planning in the U.S. Such installations may be overwhelmed by the increasing size and frequency of storms projected under climate change. Flooding due to inland rainfall, stream overflow, and coastal storms are all part of the growing disturbance factors in cities. 


\section{CONTEXT: GLOBAL URBAN CONDITIONS CONTAIN MECHANISMS \\ LOGIC SEQUENCE OF \\ FRAMEWORKS}

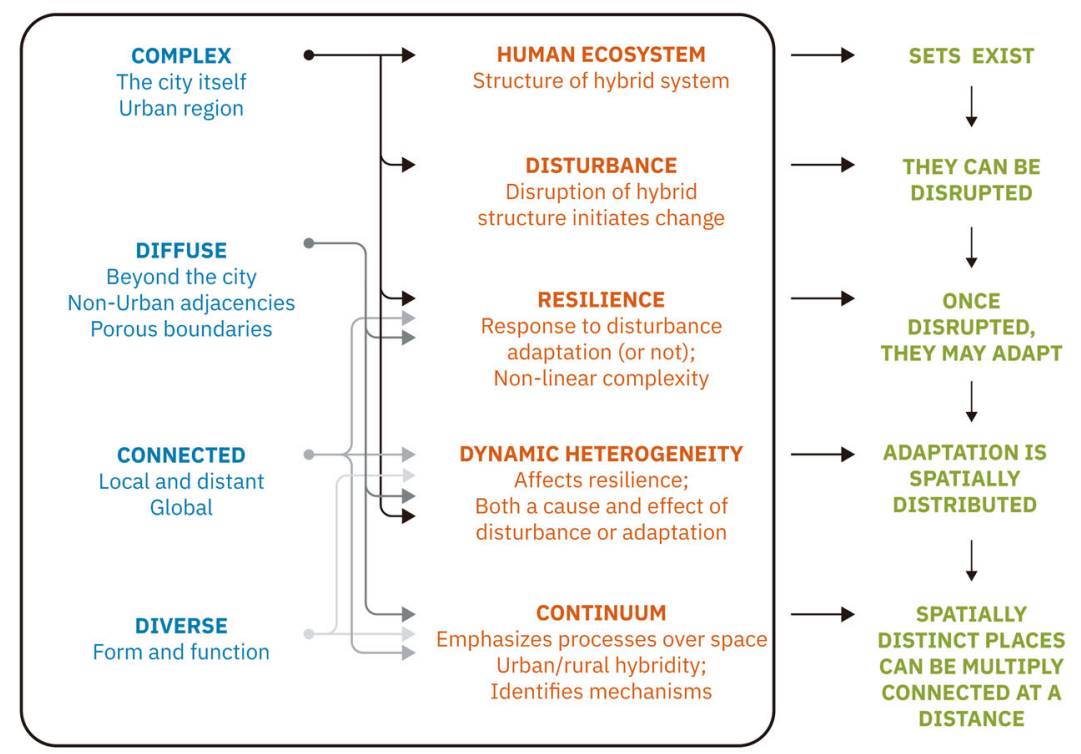

\section{METACITY}

Fig. 8 The five frameworks appear in the middle column. The global urban conditions, in the left column, provide the context or upper constraints for the mechanisms the five frameworks embody. The right column indicates how the five frameworks can be arranged in a logical sequence to inform urban ecological planning or design by specifying criteria by which projects may be evaluated.

3. If the system is disrupted, does it support ecological, social, and technological adaptive capacities to constructively react and reorganize? Green infrastructure maintenance is rarely included in plans or the actual interventions themselves. Often, local communities are assumed to take on the maintenance of bioswales, rain gardens, and the like. However, without time or financial resources, such maintenance may not be guaranteed. This impairs the contribution of green stormwater infrastructure to urban resilience.

4. How is adaptive capacity and impact spatially distributed across the system? Urban regions are home to populations and neighborhoods that differ widely in terms of wealth, disposable income, time for community activities, access to information, and power to influence environmental decision making. If plans for urban development, change, and revitalization do not take such differences into account, social inequity can result.

5. How do spatially distinctive parts of the system connect with each other and with urban and non-urban systems at various distances? How do distant connections affect system disruption and adaptation? An example of the role of connectivity in stormwater management is the impact of upstream development in watersheds. Catastrophic floods in some urban areas are associated with increasing suburban and exurban development upstream of the older urban cores. An additional example of connectivity is the infusion of urban economic resources into Chinese village areas, which has altered local lifestyles and reduced the dependence on farm-based livelihoods. Rural biodiversity has concomitantly responded in some places.

\section{CONCLUSIONS}

The frameworks promote a comprehensive view of urban systems. More focused urban conceptions driven mainly by population size, Gross Domestic (urban) Product, spatial extent, or fixed land use classifications may miss the dynamic interconnectedness and/or complexity of those urban SETS, and thereby the important roles of social and environmental quality in understanding and improving cities. Our synthesis meets several needs articulated for developing a new global urban systems science ${ }^{1,9}$. The frameworks offer a strong interdisciplinary lens on urban systems, supporting the comparative research urgently needed as a complement to the pioneering but place-based urban research that has emerged in the last few decades ${ }^{73}$. The integrated frameworks can counter the risk that problems prioritized by special interests may be oversimplified, that opportunistically identified themes may be pursued to the detriment of strategic choices, or that strictly technological response to an immediate crisis may substitute for more inclusive and systemic rosters of choices.

Urban ecosystem research is often justified by practical concerns. This synthesis shows a broad theoretical foundation for global urban science, and hence provides additional motivation for co-production and the transdisciplinary crossing of academic and professional silos that is required to promote urban sustainability. Because urban systems are complex, connected, diffuse, and diverse, others may propose alternative frameworks. A nested hierarchical approach to theory can accommodate such conceptual variety and empirical evolution ${ }^{74}$, if the key frameworks are indeed inclusive and open-ended. We hope our synthesis has shown the value of an intellectually adaptive approach to urban theory as a contribution to convergence science for the global urban realm.

Received: 28 October 2019; Accepted: 15 June 2020; Published online: 23 February 2021

\section{REFERENCES}

1. Acuto, M., Parnell, S. \& Seto, K. C. Building a global urban science. Nat. Sustain. 1, 2-4 (2018).

2. Anderies, J. M., Folke, C., Walker, B. \& Ostrom, E. Aligning key concepts for global change policy: robustness, resilience, and sustainability. Ecol. Soc. 18, 8 (2013). 
3. Brenner, N. \& Schmid, C. Planetary urbanization. In Implosions/explosions: Towards A Study of Planetary Urbanization (ed. Brenner, N.) 142-463 (Jovis Verlag, 2014).

4. Elmqvist, T. et al. Sustainability and resilience for transformation in the urban century. Nat. Sustain. 2, 267 (2019).

5. McPhearson, T. Scientists must have a say in the future of cities. Nature 538, 165-166 (2016)

6. Groffman, P. M. et al. Moving towards a new Urban Systems Science. Ecosystems https://doi.org/10.1007/s10021-016-0053-4 (2016).

7. Pataki, D. E. Grand challenges in urban ecology. Front. Ecol. Evol. 3, 57 (2015).

8. National Science Foundation. What is Convergence?|NSF-National Science Foundation. https://www.nsf.gov/od/oia/convergence/index.jsp (Accessed April 23, 2019)

9. Ramaswami, A. et al. Sustainable Urban Systems: Articulating a Long-Term Convergence Research Agenda. Vol. 31 (National Science Foundation, 2018).

10. Grimm, N. B., Pickett, S. T. A., Hale, R. L. \& Cadenasso, M. L. Does the ecological concept of disturbance have utility in urban social-ecological-technological systems? Ecosyst. Health Sustain 3, e01255 (2017).

11. McPhearson, T. et al. Advancing urban ecology towards a science of cities. BioScience 66, 198-212 (2016).

12. United Nations. Transforming Our World: the 2030 Agenda for Sustainable Development. https://sustainabledevelopment.un.org/post2015/transformingourworld (Accessed March 6, 2020).

13. Seto, K. C. et al. Urban land teleconnections and sustainability. Proc. Natl Acad. Sci. USA 109, 7687-7692 (2012).

14. Folke, C., Biggs, R., Norstrom, A. V., Reyers, B. \& Rockstrom, J. Social-ecological resilience and biosphere-based sustainability science. Ecol. Soc. 21, 41 (2016).

15. Grimm, N. B., Cook, E. M., Hale, R. L. \& Iwaniec, D. M. A broader framing of ecosystem services in cities: benefits and challenges of built, natural, or hybrid system function. In The Routledge Handbook of Urbanization and Global Environmental Change (eds. Seto, K. C., Solecki, W. D. \& Griffith, C. A.) 203-212 (Routledge, 2016).

16. Pelling, M. \& Manuel-Navarrete, D. From resilience to transformation: the adaptive cycle in two Mexican urban centers. Ecol. Soc. 16, 11 (2011).

17. Meerow, S., Newell, J. P. \& Stults, M. Defining urban resilience: a review. Landsc. Urban Plan. 147, 38-49 (2016).

18. Shane, D. G. Recombinant Urbanism: Conceptual Modeling in Architecture. (John Wiley \& Sons, 2005).

19. McHale, M. R. et al. The new global urban realm: complex, connected, diffuse, and diverse social-ecological systems. Sustainability 7, 5211-5240 (2015).

20. Ellin, N. Integral urbanism: a context for urban design. In Resilience in ecology and urban design: linking theory and practice for sustainable cities (eds. Pickett, S. T. A., Cadenasso, M. L. \& McGrath, B.) 63-78 (Springer, 2013).

21. Marcotullio, P. J. \& Solecki, W. What is a city? an essential definition for sustainability. In Urbanization and Sustainability: Linking Urban Ecology, Environmental Justice, and Environmental Change (eds. Boone, C. G. \& Fragkias, M.) 11-25 (Springer, 2013).

22. Burch, W. R., Jr., Machlis, G. E. \& Force, J. E. The Structure and Dynamics of Human Ecosystems: toward A Model for Understanding and Action. (Yale University Press, 2017)

23. Redman, C., Grove, J. M. \& Kuby, L. Toward a Unified Understanding of Human Ecosystems: Integrating Social Sciences Into Long-term Ecological Research. Vol. 13 (LTER Network, 2000).

24. Barnett, R. \& Margetts, J. Disturbanism in the South Pacific: disturbance ecology as a basis for urban resilience in small island states. In Resilience in Ecology and Urban Design: Linking Theory and Practice for Sustainable Cities (eds. Pickett, S. T. A., Cadenasso, M. L. \& McGrath, B.) 443-459 (Springer, 2013).

25. Folke, C. et al. Resileince and Sustainable Development: Building Adaptive Capacity in A World of Transformations. (Ministry of the Environment, 2002).

26. Scheffer, M., Westley, F., Brock, W. A. \& Holmgren, M. Dynamic interaction of societies and ecosystems-linking theories from ecology, economy, and sociology. In Panarchy: Understanding Transformations in Human and Natural Systems (eds. Gunderson, L. H. \& Holling, C. S.) 195-239 (Island Press, 2002).

27. Pickett, S. T. A. et al. Dynamic heterogeneity: a framework to promote ecological integration and hypothesis generation in urban systems. Urban Ecosyst. 20, 1-14 (2017).

28. Wu, J. G. \& Loucks, O. L. From balance of nature to hierarchical patch dynamics: a paradigm shift in ecology. Q. Rev. Biol. 70, 439-466 (1995).

29. Boone, C. G. et al. Reconceptualizing land for sustainable urbanity. In Rethinking Urban Land Use in A Global Era (eds. Seto, K. C. \& Reenberg, A.) 313-330 (MIT Press, 2014).

30. Machlis, G. E., Force, J. E. \& Burch, W. R. The human ecosystem 1. The human ecosystem as an organizing concept in ecosystem management. Soc. Nat. Resour. 10, 347-367 (1997).

31. Cadenasso, M. L. \& Pickett, S. T. A. Three tides: the development and state of the art of urban ecological science. In Resilience in Ecology and Urban Design: Linking
Theory and Practice for Sustainable Cities (eds. Pickett, S. T. A., Cadenasso, M. L. \& McGrath, B.) 29-46 (Springer, 2013).

32. Collins, S. L. et al. An integrated conceptual framework for long-term socialecological research. Front. Ecol. Environ. 9, 351-357 (2011).

33. Naveh, Z. The total human ecosystem: integrating ecology and economics. BioScience 50, 357-361 (2000).

34. Pickett, S. T. A. \& Cadenasso, M. L. Ecosystem as a multidimensional concept: meaning, model and metaphor. Ecosystems 5, 1-10 (2002).

35. Alberti, M. Advances in Urban Ecology: Integrating Humans and Ecological Processes in Urban Ecosystems. (Springer, 2008).

36. Pickett, S. T. A. \& Grove, J. M. Urban ecosystems: what would Tansley do? Urban Ecosyst. 12, 1-8 (2009).

37. Lachmund, J. Greening Berlin. (MIT Press, 2013).

38. Rademacher, A., Cadenasso, M. L. \& Pickett, S. T. A. From feedbacks to coproduction: toward an integrated conceptual framework for urban ecosystems. Urban Ecosyst. https://doi.org/10.1007/s11252-018-0751-0 (2018).

39. Johnson, E. A. \& Miyanishi, K. (eds.) Plant Disturbance Ecology: the Process and the Response. (Academic Press, Burlington, 2007).

40. Pickett, S. T. A. \& White, P. S. (eds.) The Ecology of Natural Disturbance and Patch Dynamics. (Academic Press, Orlando, 1985).

41. Schumpeter, J. A. The Theory of Economic Development: an Inquiry Into Profits, Capital, Credit, Interest, and the Business Cycle. (Transaction Books, 1983).

42. Peters, D. P. C. et al. Cross-system comparisons elucidate distrubance complexities and generalities. Ecosphere 2, art 81 (2011).

43. Holling, C. S. Engineering resilience versus ecological resilience. In Engineering within Ecological Constraints (ed. Schulze, P. C.) 31-44 (National Academies of Engineering, 1996).

44. Gunderson, L. H. \& Holling, C. S. (eds.) Panarchy: understanding transformations in human and natural systems. (Island Press, Washington DC, 2002).

45. Walker, B., Holling, C. S., Carpenter, S. R. \& Kinzig, A. Resilience, adaptability and transformability in social-ecological systems. Ecol. Soc. 9, Article 5 (2004).

46. McPhearson, T., Andersson, E., Elmqvist, T. \& Frantzeskaki, N. Resilience of and through urban ecosystem services. Ecosyst. Services 12, 152-156 (2015).

47. Tidball, K., Frantzeskaki, N. \& Elmqvist, T. Traps! An introduction to expanding thinking on persistent maladaptive states in pursuit of resilience. Sustain. Sci. 11, 861-866 (2016).

48. Biggs, R., Westley, F. R. \& Carpenter, S. R. Navigating the back loop: fostering social innovation and transformation in ecosystem management. Ecol. Soc. 15, 9 (2010).

49. Changnon, S. A., Kunkel, K. E. \& Reinke, B. C. Impacts and responses to the 1995 heat wave: a call to action. Bullet. Am. Meteorol. Soc. 77, 1497-1506 (1996).

50. Borden, K. A. \& Cutter, S. L. Spatial patterns of natural hazards mortality in the United States. Int. J. Health Geogr. 7, 64 (2008).

51. Park, R. E. \& Burgess, E. W. The City (University of Chicago Press, 1925).

52. Jacobs, J. The Death and Life of Great American Cities (Random House, 1961).

53. Lynch, K. Good City Form (MIT Press, 1981).

54. Shane, D. G. Urban Design Since 1945-A Global Perspective (John Wiley \& Sons, Ltd, 2011).

55. Hamstead, Z., Farmer, C. \& McPhearson, T. Landscape-based extreme heat vulnerability assessment. J. Extreme Event. 5, 1-23 (2018).

56. Uejio, C. K. et al. Intra-urban societal vulnerability to extreme heat: the role of heat exposure and the built environment, socioeconomics and neighborhood stability. Health Place 17, 498-507 (2011)

57. Rosenthal, J. K., Kinney, P. L. \& Metzger, K. B. Intra-urban vulnerability to heatrelated mortality in New York City. 1997-2006. Health Place 30, 45-60 (2014)

58. Madrigano, J., Ito, K., Johnson, S., Kinney, P. L. \& Matte, T. A case-only study of vulnerability to heat wave-related mortality in New York City (2000-2011). Environ. Health Perspect. 123, 672-678 (2015).

59. Allen, T. F. H. \& Starr, T. B. Hierarchy: Perspectives for Ecological Complexity (2nd edn.) (University of Chicago Press, Chicago, 2017).

60. McGrath, B. \& Shane, G. Introduction: metropolis, megalopolis, and metacity. In The SAGE Handbook of Architectural Theory (eds. Crysler, C. G., Cairns, S. \& Heynen, H.) (SAGE, 2012).

61. Mihaljevic, J. R. (2012). Linking metacommunity theory and symbiont evolutionary ecology. Trends Ecol. Evol. 27, 323-329 (2012).

62. McGrath, B., Sangawongse, S., Thaikatoo, D. \& Corte, M. B. The architecture of the metacity: land use change, patch dynamics and urban form in Chiang Mai, Thailand. Urban Plan. 2, 53-71 (2017).

63. Leibold, M. A. The metacommunity concept and its theoretical underpinnings. In The Theory of Ecology (eds. Scheiner, S. M. \& Willig, M. R.) 163-183 (University of Chicago Press, 2011).

64. McGrath, B. \& Pickett, S. T. A. The metacity: a conceptual framework for integrating ecology and urban design. Challenges 2011, 55-72 (2011).

65. Batty, M. The New Science of Cities. (MIT Press, 2013).

66. Gandy, M. Where does the city end? In Implosions/explosions: Towards A Study of Planetary Urbanization (ed. Brenner, N.) 86-89 (jovis Verlag, 2014). 
67. McPhearson, T., Kremer, P. \& Hamstead, Z. Mapping ecosystem services in new york city: applying a social-ecological approach in urban vacant land. Ecosyst. Service 11-26, https://doi.org/10.1016/j.ecoser.2013.06.005 (2013).

68. Kremer, P., Hamstead, Z. \& McPhearson, T. A social-ecological assessment of vacant lots in New York City. Landsc. Urban Plann. 218-233, https://doi.org/ 10.1016/j.landurbplan.2013.05.003 (2013).

69. Burkholder, S. The new ecology of vacancy: rethinking land use in shrinking cities. Sustainability 4, 1154-1172 (2012).

70. Bowman, A. O. M. \& Pagano, M. A. Transforming America's cities: policies and conditions of vacant land. Urban Affairs Rev. 35, 559-581 (2000).

71. Kabisch N., et al. Nature-Based Solutions to Climate Change Adaptation in Urban Areas_Linkages Between Science, Policy and Practice. 91-109 (Springer, 2017).

72. Schwarz, K., Berland, A. \& Herrmann, D. L. Green, but not just? Rethinking environmental justice indicators in shrinking cities. Sustain. Cities Soc. 41, 816-821 (2018)

73. McDonnell, M. J. \& Hahs, A. K. The future of urban biodiversity research: moving beyond the 'low-hanging fruit'. Urban Ecosyst. 16, 397-409 (2013).

74. Pickett, S. T. A., Kolasa, J. \& Jones, C. G. Ecological Understanding: The Nature of Theory and the Theory of Nature (Academic Press, 2007).

75. Depietri Y. \& McPhearson T. Integrating the grey, green, and blue in cities: Nature-based solutions for climate change adaptation and risk reduction. In Nature-based solutions to climate change adaptation in urban areas. Theory and practice of urban sustainability transitions (eds. Kabisch N., Korn H., Stadler J. \& Bonn A.) (Springer, Cham, 2017).

\section{ACKNOWLEDGEMENTS}

W.Z. thanks the support from the National Natural Science Foundation of China (41422104 and 41371197) and the Key Research Program of Frontier Sciences, CAS (QYZDB-SSW-DQC034). S.T.A.P. is grateful for a visiting professorship funded by the Chinese Academy of Sciences President's International Fellowship Initiative (2013T1Z0026), and both authors acknowledge the U.S National Science Foundation for support of the Baltimore Ecosystem Study LTER (DEB-1855277) and the Urban Sustainability Research Coordination Network. T.M. is grateful for support from the US National Science Foundation through the Urban Resilience to Extreme WeatherRelated Events Sustainability Research Network (NSF grant no. SES 1444755), as well as the US NSF Accel-Net program NATURA (grant no. 1927167), and US NSF Convergence program (grant no. 1934933). Research was also partially funded through the 2015-2016 BiodivERsA COFUND call for research proposals, with the national funders the Swedish Research Council for Environment, Agricultural Sciences, and Spatial Planning; the Swedish Environmental Protection Agency; the German Aerospace Center; the National Science Centre, the Research Council of Norway; and the Spanish
Ministry of Economy and Competitiveness. Additional support for T.M. was provided by the SMARTer Greener Cities project through the Nordforsk Sustainable Urban Development and Smart Cities program. We are grateful for strong graphics support from Claudia Tomateo in the Urban Systems Lab, the New School.

\section{AUTHOR CONTRIBUTIONS}

W.Z. and S.T.A.P. conceived the study, and W.Z., S.T.A.P., and T.M. wrote the manuscript.

\section{COMPETING INTERESTS}

The authors declare no competing interests.

\section{ADDITIONAL INFORMATION}

Correspondence and requests for materials should be addressed to W.Z.

Reprints and permission information is available at http://www.nature.com/ reprints

Publisher's note Springer Nature remains neutral with regard to jurisdictional claims in published maps and institutional affiliations.

\begin{abstract}
c) (i) Attribution 4.0 International License, which permits use, sharing, adaptation, distribution and reproduction in any medium or format, as long as you give appropriate credit to the original author(s) and the source, provide a link to the Creative Commons license, and indicate if changes were made. The images or other third party material in this article are included in the article's Creative Commons license, unless indicated otherwise in a credit line to the material. If material is not included in the article's Creative Commons license and your intended use is not permitted by statutory regulation or exceeds the permitted use, you will need to obtain permission directly from the copyright holder. To view a copy of this license, visit http://creativecommons. org/licenses/by/4.0/.
\end{abstract}

Open Access This article is licensed under a Creative Commons

(C) The Author(s) 2021 